\title{
Construction of Backup Center for Enterprise Electronic Files Based on Cloud Platform
}

\author{
Zhang Wenjie, Li Wei, Jin Chengming, Chen Shuo, Zheng shanqi \\ State Grid Liaoning Electric Power Co. Ltd, Information communication branch, Liaoning Shenyang, 110006, China
}

\begin{abstract}
The development in information technologies lies such as cloud platform provide good ways to improve the intelligence of present electrical enterprises. However, the massive data from the power stations and systems should be properly stored to avoid the sudden breakdowns of the system. Therefore, it is meaningful to construct the data backup center for all the data in the enterprise. The main objective to the properly manage and analyze these data to find and solve the potential threats in the enterprise system. This paper analyses the main functions of the data backup center and provides some potential ways to build it with high intelligence and automation level. By using stable facilitations, intelligent information classification modules and automatic anomaly detection tools, the data backup center could help the smooth operating of the whole enterprise.
\end{abstract}

\section{Introduction}

The progress in information technology makes it convenient to transmit and share electronic files and other data through the high-speed networks [1-5]. As an essential part of people's daily life, the electrical power system highly depends on the data management system. However, nowadays, there are many virus or attacks on the local networks, which may cause severe breakdowns in the power system and affect the safety [6-10]. As a remedy, many data backup technologies have been developed to avoid the serious results caused by data breakdown. To maintain the smooth operating of the whole power system, some data backup measures should be taken by the electric enterprises. Although there were some related works in the previous works, they did not consider the whole enterprise system in a unified way. Therefore, it is still necessary that more efforts should be made to apply the advanced technologies into the practical management of the power system [11-15].

In this study, we study on the construction of the data backup center in the electric enterprise. The electric enterprise should consider all its power stations or systems as a whole and take the problems of data backup seriously. At first, all the data from the power stations or systems should be transmitted to a specifically designed data center to be stored and managed [16-21]. In addition to the function of data storage, the data backup center should also do the jobs like information classification, detection, etc. through the intelligent analysis, the redundant data can be removed and the anomaly or problems can be reported in time. The large amount of historical data in the center could also provide effective training sources for the automatic learning through artificial intelligence. In summary, the main objectives of constructing the data backup center are data storage, management and intelligent analysis. To achieve such objectives, the data backup center should have reliable hardware and software. In addition, the whole system should have good robustness to the possible virus, attacks and other problems. the Therefore, by the construction of the data backup center, the efficiency and automation level of the power enterprise can be greatly enhanced.

\section{Objective of Data Backup Center}

Obviously, the main objective of the construction of data backup center is to store the data from different power stations or systems. However, the backup center should also provide other functions like information analysis and decision support.

\subsection{Data storage}

The power enterprise may comprise of many power stations or systems at different locations. So, it is necessary that all these data are collected together and analyzed to maintain the successful running of the whole system. However, the local storage or networks may be destroyed by the virus, attacks or other problems. Hence, the data backup center could help regain these historical data. By the construction of the data backup center, all the relevant data with the power enterprise can be properly stored and managed. 


\subsection{Data analysis}

In the data backup center, there is a large amount of data from different power stations and systems, which may contain much redundancy. In order to manage these data with high efficiency, the backup center should make analysis on them to classify them into several categories. Meanwhile, the redundancy should be eliminated to relieve the storage burden of the backup center. Some automation tool can be employed to detect the anomaly or problems in the data flows so these problems can be reported to the operators in time. So, the detected problems or potential threats can be solved with high efficiency.

\section{Construction of Backup Center for Enterprise Electronic Files}

\subsection{Stable and robust facilitations}

The stability and robustness are the necessary properties of a data backup center. Both the hardware and software should be carefully selected and designed to keep them operated smoothly for a long time. The whole system should be able to resist the possible virus or attacks to avoid the destruction for the stored data and system. Therefore, the facilitations in the data backup center should be stable and robust.

\subsection{Intelligent data classification}

With the reliable facilitations, the data transmitted from different power stations or systems can be stored. However, there is much redundancy in it, which should be eliminated. As a remedy, some intelligent data classification module should be incorporated in the data backup system. In this way, all the data can be classified as several focused categories so they can be managed more efficiently. In addition, the redundant information can be removed to relive the total storage. So, based on the intelligent data classification, the data from all the power stations and systems can be managed with high efficiency.

\subsection{Automatic anomaly detection}

Based on the classified categories from intelligent classification modules, the automatic anomaly detection modules are developed to find the potential threats in each category. The large amount of historical data in the backup center provide rich training sources for the anomaly detection models. So, using automatic anomaly detection modules, the problems in the power system can be detected and located in time. Furthermore, these problems can be labelled based on the historical data. Then, the corresponding strategies can be reported to help the operators to handle these problems.

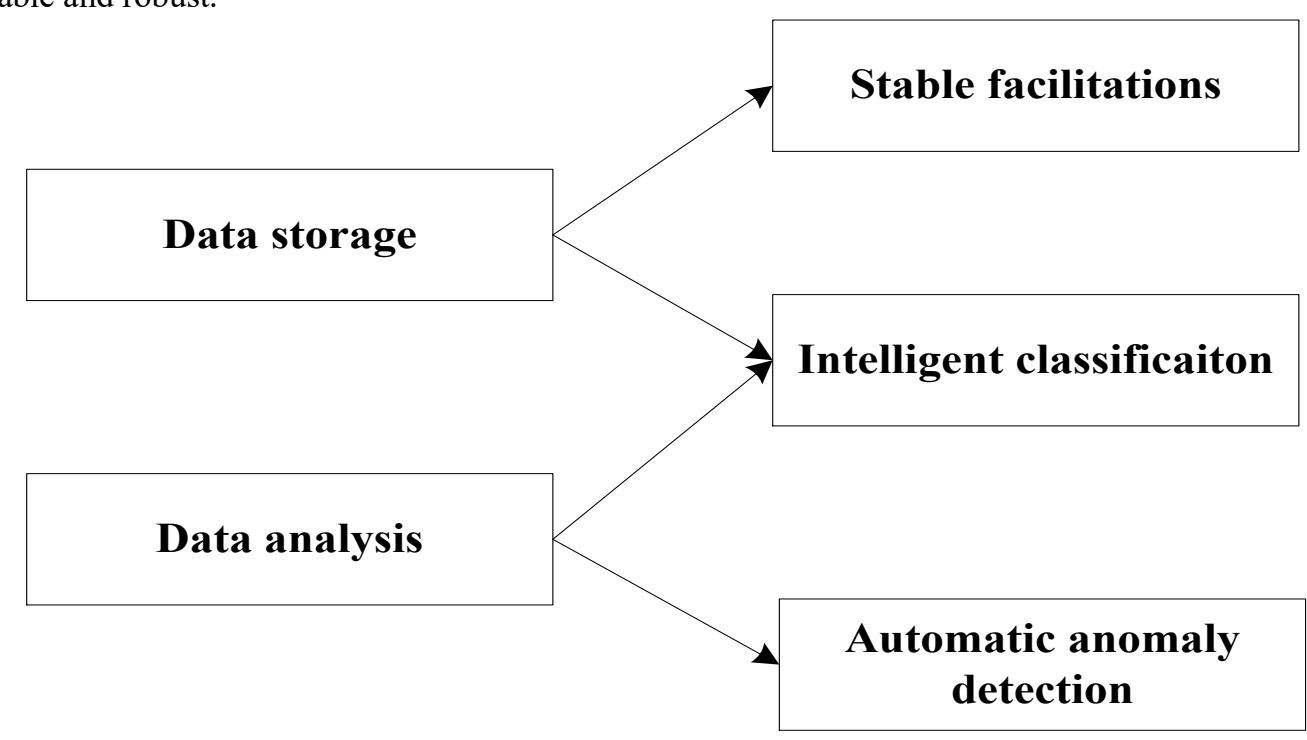

Fig. 1 The main objectives and functions of the constructed data backup center.

\section{Conclusion}

In this paper, we study on the construction of backup center for the electronic files in the power enterprise. The backup center is constructed to storage the massive data from the power stations and systems and analyse simultaneously. To achieve such functions, the backup center should have stable facilitations, intelligent classification modules, and automatic anomaly detection modules. With the help of the data backup center, the overall robustness of the power system and intelligence can be greatly enhanced.

\section{Acknowledgement}

Funding: This work was supported by the Project of Improving Technological Innovation Ability and Mass Innovation Research (Grant No. 5222XT180033).

\section{References}

1. Borlea I, Buta A and Dusa et al. 2005 DIASE-Expert system fault diagnosis for Timisoara $200 \mathrm{kV}$ Substation in Proc. EUROCON pp 221-224. 
2. Wang Y and Pan Z 2011 Study on test technology of smart substation secondary system in Proc. International Conference on Consumer Electronics, Communications and Networks pp 1-4.

3. Kezunovic M 2009 Substation fault analysis requirement in Proc. IEEE Power \& Energy Society General Meeting pp 1-2.784-787

4. Lian J, Li H and Song K 2011 The analysis and corrective measures of common problems of $10 \mathrm{kV}$ capacitor bank in substation in Proc International Conference on Advanced Power System Automation and Protection pp 1750-1752

5. Gogan P L and Wyckoff G D 2012 Design and construction of sustainable substations in Proc. PES T\&D pp 1-4.

6. Li Q, Zhou Z and Du D, et al. 2013 A novel substation area backup protection for smart substation in Proc. IEEE PES Asia-Pacific Power and Energy Engineering Conference pp 1-4.

7. Wang Z, Jin $\mathrm{N}$ and Zhang J, et al. 2014 Fault information and diagnosis modelling of on-line communication monitoring system for digital substation in Proc. IEEE PES General Meeting | Conference \& Exposition pp 1-5.

8. Liu Y, Gao H and Gao W, et al. 2017 Development of a substation-area backup protective relay for smart substation IEEE Transactions on Smart Grid vol 8 no 6 pp 2544-2553.

9. Zhang H, Dou R and Zhi M, et al. 2016 The technology of interlocking logic visualization for smart substation in Proc. China International Conference on Electricity Distribution pp 1-4.

10. Li Z and Ma Q 2018 Discussion on optimization measures of relay protection technology in intelligent substation in Proc. IEEE Advanced Information Management, Communicates, Electronic and Automation Control Conference pp 1593-1596.

11. Topolsky D V, ToPolskaya I G and Topolsky N D 2018 Development of an intelligent measuring system for digital substations in Proc. pp International Multi-Conference on Industrial Engineering and Modern Technologies 1-4.

12. Nassu B T, Lourival L and Bruno $M$ et al. 2018 Image-based state recognition for disconnect switches in electric power distribution substations in Proc. SIBGRAPI Conference on Graphics, Patterns and Images pp 432-439.

13. Nichani A M and Swarup S 2018 Modelling and simulation of digital substation automation for intersubstation line protection in Proc. National Power Systems Conference pp 1-6.

14. Gao X and Wang Y 2013 Research of digital community service platform based on cloud computing in Proc. 8th International Conference on Computer Science \& Education pp 1-4.

15. Koo J, Kin Y and Lee S 2019 Security Requirements for Cloud-based C4I Security Architecture in Proc.
International Conference on Platform Technology and Service (PlatCon) pp 1-4.

16. Cheng G 2010 Data center management plan in cloud computing environment in Proc. International Conference on Information Management, Innovation Management and Industrial Engineering pp 376-380.

17. Cheng G 2010 Data center management plan in cloud computing environment in Proc. International Conference on Information Management, Innovation Management and Industrial Engineering pp 393-396.

18. Qin X, Lin B and Ma S, et al. 2014 Study of the application of active power adjustment and control technology based on modem energy storage into power system stability control and voltage adjustment in Proc. International Conference on Power System Technology pp 1-4.

19. Song S, Bin T and Yang Q. 2005 Study on wide area measurement system based transient stability control for power system in Proc. International Power Engineering Conference pp 1-4.

20. Sun A, Zhou J and Ji T, et al. 2011 CSB: Cloud service bus based public SaaS platform for small and median enterprises in Proc. International Conference on Cloud and Service Computing pp 321-324.

21. Chung K and Keum C. 2014 Access control management of the innovation cloud service platform in Proc. International Conference on Information and Communication Technology Convergence pp 1-4. 